\title{
NOTAS
}

\section{EL ALFABETO Y SUS NINFAS EN LOS SIGLOS XVI Y XX ALEJANDRO SYLVANO Y PEDRO SALINAS}

Plutarco -o el escritor galardonado con el nombre del célebre polígrafo de la Antigüedad-en su Vida y poesía de Homero enseñaba que los poemas épicos fundadores solían ocultar una sabiduría alegórica, y que eran susceptibles de interpretarse mediante su léxico e imágenes, ya que todo iba revestido de un lenguaje que el mismo PseudoPlutarco llamó mítico y enigmático ${ }^{1}$. Este experimento de lectura de Homero según sus presuntos enigmas se hizo compatible con una corriente de pensamiento esotérico del siglo III, cuando los neoplatónicos se ocupaban en cimentar doctrinas como la de la armonía cósmica y la de la gran alma secreta, inmanente detrás de los fenómenos. Al lado de una exégesis homérica basada en la solución de enigmas, la explícita, la exotérica no tenía sino un valor estético o moralizador ${ }^{2}$.

Un genio sobresaliente de esa escuela, Porfirio -cuyas doctrinas llegaron a ser fuente de los neoplatónicos latinos, san Agustín inclusive-, escribió un texto intitulado De la cueva de las ninfas, en cuyo tercer capítulo se conjetura que Homero poetiza una alegoría para comunicar cierta doctrina metafísica y cósmica ${ }^{3}$. Aparece el texto homérico inmediatamente después del punto central de la Odisea, o sea que ocupa los versos 102 a 112 del libro XIII. Consta, pues, de solos once versos y ofrece una descripción de la cueva que abarca nueve elementos materiales: $i$ ) un olivo; ii) la misma cueva; iii) unas crate-

${ }^{1}$ Essay on the life and poetry of Homer, ed. and tr. John J. Keaney \& Robert Lamberton, Scholars Press, Atlanta, GA, 1986. "Mítico y enigmático" se lee en el cap. 92 (pp. 152-157).

2 Robert Lamberton, Homer the theologian. Neoplatonist allegorical reading and the growth of the epic tradition, University of California Press, Berkeley-Los Angeles, 1986. Sobre Pseudo-Plutarco, p. 40. Acerca de las raíces de la tradición platónica en la interpretación de alegorías homéricas, p. 92.

3 The cave of the nymphs in the Odyssey, ed. rev. and tr. Leendert Westerink et al., State University of New York at Buffalo, Buffalo, NY, 1969. 
ras de piedra; $i v)$ unas jarras con orejeras, de piedra; $v$ ) algunas abejas que acopian su miel; vi) unos telares, también pétreos; vii) algunas telas teñidas de púrpura; viii) dos manantiales perennes de agua, y $i x)$ dos entradas, una para los mortales y otra para los inmortales. Según vaticina Porfirio la cueva y el léxico que la evoca y el que representa su entorno y contenido revisten una significación más profunda, y a la vez trascendental (cap. 21). El olivo que preside afirma la coherencia del enigma todo (cap. 22), y el neoplatónico concluye que, en efecto, el poeta ha esbozado, por medio de esos nueve elementos, el plan de una armonía tan inmanente como inmaterial (cap. 36).

Durante la Edad Media el enigma no fue mucho más que una adivinanza, una de las "formas sencillas" de la creatividad "popular", de acuerdo con André Jolles, quien señala el uso de la adivinanza preliteraria como un modo de saber si un interrogado era miembro de cierto clan, de algún grupo que poseyera sabiduría oculta o si pertenecía a algún círculo de iniciados ${ }^{4}$. Aparecieron luego las primeras colecciones de adivinanzas impresas, como el Strassburger Räthselbuch (1505), y colecciones en latín con propósitos didácticos que enseñaban, entre otras materias, el alfabeto mediante la solución de un enigma. En los Aenigmatum libri III de Johannes Lorichius (muerto en 1559) se reproduce una adivinanza cuya solución es literae vocales et consonantes; se trata de fonemas, de letras como signos, de sonidos emitidos por la voz. No hay por ahora posibilidad de personificar las letras, a no ser en aquellas adivinanzas de Estrasburgo donde las cinco vocales representaban a los "intérpretes" que hacían posible que los dieciocho "extranjeros" pudieran entenderse ${ }^{5}$.

Explica Antonio Alatorre, en su magistral introducción a los enigmas de sor Juana Inés de la Cruz, cómo esta "forma sencilla" se puso de moda en las cortes renacentistas como juego de ingenio en los saraos ${ }^{6}$. Esta moda, ya de hombres de letras, empezó en las pequeñas cortes de Italia, luego pasó a París. En 1576 se estableció la Academia del Palacio, gran protectora del platonismo italianizante $-\mathrm{O}$ per le donne - y de los enigmas como actividad de gente culta, medio seria, medio jocosa ${ }^{7}$. Cinco años más tarde apareció el libro de Ale-

${ }^{4}$ Einfache Formen, 4 a ed., Tübingen, 1968. Sobre adivinanzas, pp. 134-136.

${ }^{5}$ Quisiera expresar mi profundo agradecimiento para con el profesor HansJörg Uther, director de redacción de la Enzyklopädie des Märchens en Göttingen (Alemania), por haberme orientado en el tema de los primeros libros impresos de enigmas.

${ }^{6}$ Sor Juana InÉs de la Cruz, Enigmas ofrecidos a la Casa del Placer, ed. y est. A. Alatorre, El Colegio de México, México, 1994. Sobre enigmas literarios, pp. 42-46. Alatorre cita la definición de Covarrubias en su Tesoro: "qüestión y pregunta engañosa y entrincada... escura alegoría” (p. 39).

7 T. F. Crane, Italian social customs of the sixteenth century, Yale University Press, New Haven, CT, 1920. Con respecto al enigma en Italia, sobre todo las Piacevoli notti 
jandro Sylvano, Quarenta aenigmas en lengua espannola, dedicado a la joven reina viuda inconsolable, residente lejos de la corte ${ }^{8}$. Era un momento triste en Francia toda, en vista de las guerras civiles y la intervención española (esta última trajo consigo, por lo menos, una época de contacto entre los hablantes de ambas lenguas).

Nació Alejandro Sylvano, originalmente Alexandre vanden Bussche, en Audenarde (Flandes) en 1530. Tras haber sido soldado en los ejércitos de Carlos V pasó a la corte de los Este en Ferrara y, finalmente, a la de los Valois en $1559^{9}$. En la recopilación que hace Sylvano los primeros nueve enigmas son de su composición-quizá de su adaptación del italiano-y en cada caso ha ocultado, al reverso de la hoja, la solución apropiada. El poema que nos interesa tiene treinta y tres versos, o sea treinta y cuatro menos la pregunta final, y abarca nueve enunciados ${ }^{10}$. Se respeta aquí la ortografía y la puntuación del original:

Aenigma Primera del Sylvano

[i] Hermanas ay dos dozenas,

Feas no, aunque morenas

Que hazen en pocos momientos [sic]

Mil amantes muy contiéntos [sic]

[ii] Mas qu'ellas blanca es su madre,

[iii] Muy blanco es tambien su padre

Pero no puede engendrar

Sino [sic] quiere se baxar

So la muger laqual haze

Des pues del lo que le plase.

[iv] Poco apoco estas donzellas

Suffren que se goze d'ellas

Pero no juntas se dan

Antes apartadas van

de Gianfrancesco Straparola (1556), de quien Sylvano tomó algunos enigmas, pero evidentemente no la "Aenigma primera", pp. 291-294. Sobre la llegada del enigma a Francia, pp. 476-479.

8 QVARENTA aENIGMaS en LENGVA espannola. Dirigidas a la Magestad della serenissima Reyna Doña Ysabel De-Avtraia Biuda del Rey de Francia, Don Carlos Noveno. EN PARIS, En la casa de Giles Beys, calle S. Iago, al Lirio Blanco. MDLXXXI CON PRIVILEGIO DEL REY [Empresa: un lirio y el lema "CASTA PLACENT SUPERIS"]; 26 hojas de enigmas en castellano hasta al final: FORTIS FRAENAT FORTVNAM.

${ }^{9}$ Bibliotheca Belgica, eds. Ferdinand van den Haeghen \& Marie-Thérèse Lenger, Bruselas, 1964, "Bussche, Alexandre vanden, le Sylvain", t. 1, pp. 400-416. Sylvano tiene cierta fama debido a sus Cent histoires tragiques (1581), libro de anécdotas en el cual aparece la versión luego traducida al inglés de la leyenda de "la libra de carne exigida al deudor", aprovechada poco después por Shakespeare como motivo central de El mercader de Venecia.

${ }^{10}$ La crítica literaria numerológica ha investigado las fuerzas ocultas evocadas por escritores del pasado que se han valido de los números nueve y treinta y tres. 
Doz a doz, y tres, a tres

Seis, y siete alguna vez.

[v] Tambien hazen gol pear [sic]

$\mathrm{Al}$ que no las quiere amar

[vi] Sin trabajo nose alcança

Gozo d'ellas ny holgança

[vii] Alas vezes mil trabajos

Vienen d'ellas con enojos,

Sin qu'ellas sean culpadas,

Sino les [sic] gentes malvadas,

Que las emplean en mal

[viii] Tambien ellas per [sic] igual

Quentan nuevas maravillosas

Verdaderas, y dudosas,

Porque van por toto [sic] el mundo

Y por mar sin ver el hondo,

[ix] Sin mudar de qualidad

Dizen mentira y verdad,

Que no ay venguença $[s i c]$ en ellas.

Pues quien son estas donzellas?

Acto seguido Sylvano explica la qüestion y pregunta engañosa y entrincada, en la Exposition [sic] primera del Sylvano:

La Aenigma passada significa las letras a. b. c. y otras sin las quales no se puede escrivir, la madre d'ellas es la pluma y su padre el papel que se pone debaxo, los amantes, son los estudioses [ sic], y los ninnos son golpeados por ellas quando no quieren aprender, los trabajos [que] vienen d'ellas son las falcedades y processos, las muevas [ $\mathrm{sic}]$ que quentan son las Cartas que se escriven por todo el mundo. Lo de mas s'entiende facilmente.

Después de ofrecida la solución, la Aenigma primera aún queda como poema, y como poema que ostenta varios tópicos del momento neoplatónico cortesano. Para empezar, sería interesante fijar la atención en los verbos del poema que connotan el deseo erótico: hacer contentos (a amantes), engendrar (una obra literaria u otra), alcanzar gozo y alcanzar holganza, y dos verbos que pueden ser anfibológicos: darse (existir, pero también entregarse) y emplear (servirse de, pero también cortejar) ${ }^{11}$. Los cortesanos pueden haberse familiarizado con todo esto gracias a la traducción francesa del Simposio de Platón, por Louis le Roy, dedicada a Francisco II (1555). Así, en boca de Aga-

${ }^{11}$ El Dicc. Aut. define empleo en una acepción: "Se llama entre los Galanes la dama a quien uno sirve y galantea..., [entre los de la germanía] hurto". El Tesoro de Covarrubias, s. v. darse, ofrece "rendirse" y "ocuparse" (darse a las letras, darse al vicio, etc.), además de "existir". 
tón: "Eros tiene el poder de convertir a los simples escritores en poetas... es maestro de todas las formas de la creación literaria o artística" (196d-e en las ediciones modernas), y, según la declaración de Diótima, "La composición es un ejemplo de la creación, como parte de la tarea de Eros" (ibid., 205b-c). Engendrar la obra literaria por la madre (la pluma) en el padre (el papel) quizá debe su singularidad a las obligaciones del género gramatical. Así y todo, los versos se pueden leer como parodia de la doctrina del neoplatónico León Hebreo (traducido al francés en 1551): “...l'amante è l'agente de la servitù de l'amore, ma non de la generazion sua, e l'amato è il recipiente del servizio de l'amante, ma non de la causalità de l'amore..."12. La expresión "feas no, aunque morenas", recuerdo del topos bíblico nigra sed formosa, se justifica en Sylvano pues aquella corte está fuertemente italianizada; un antipetrarquismo semiserio se ha asomado primero en Italia, luego lo ha hecho por todas partes ${ }^{13}$.

En la época de los Quarenta aenigmas había también la moda de los capricci, otra vez una corriente que primero se dio en Italia, en las cortes que conoció Sylvano. No sólo en la música y en las artes plásticas se buscaba el equivalente de lo grotesco: había, de igual manera, obras literarias que ostentaban ingeniosas alegorías y personificaciones. Un impulsor de todo esto fue aquel quidam Cesare Caporali, que en el Viaggio di Parnaso, su "capricho reverendo" -los términos son de Miguel de Cervantes-, acaba la Primera parte (1582) con la personificación no de las letras del alfabeto, sino de los signos de puntuación:

Io pur verso la cima me ne giva,

Allor che da una virgola fui giunto,

Che me giurò persona fugitiva,

E mi fe' ritener da un piccol punto.

Apuntan los biógrafos que Sylvano, en una época anterior a la de su entrada en la corte de los Valois, había dado con sus huesos en la cárcel. No se sabe por qué, si por culpa de "falcedades y processos"14, o si por "letras empleadas en mal" por "gentes malvadas". De todas maneras, habría sido algo que tendría que ver con "las cartas que se escriven por todo el mundo". Era éste precisamente el momento del

12 Dialoghi d'amore, ed. Santino Caramella, Laterza, Bari, 1929, p. 229. Sylvano había publicado una obra propia, Le dialogue de l'amour honneste (1575). La traducción posterior de León Hebreo al castellano por Garcilaso el Inca confunde la identidad de los amantes, y arruina al argumento de León Hebreo.

${ }^{13}$ La cita quizás mejor conocida sería la de Camões ("Endechas a Bárbara escrava", ca. 1575): "Pretos os cabelos, / Onde o povo vão / Perde opinião / Que os louros são belos. / Pretidão de Amor....".

${ }^{14}$ Sylvano publicó, asimismo, un libro intitulado Procès tragiques (1575). 
triunfo de otro género, el de las colecciones, en lenguas vernáculas, de cartas de o acerca de personalidades, inclusive amantes, de renombre. La moda empezó con la recopilación de Pietro Aretino (1537) y luego pasó a Francia en traducciones ${ }^{15}$. La primera colección en francés, que llevaba, además, un panegírico del género, fue transmitida -o tal vez inventada en gran parte- por Étienne du Tronchet, otro servidor de la casa de Valois, secrétaire de la Royne mère Catalina de Médicis, suegra de la reina viuda a quien servía Sylvano, en sus Lettres missives et familieres (1569). Cuando Tronchet celebra "las Cartas que se escriven por todo el mundo", además de las "dos dozenas" de letras que las facilitan, está saludando las letras que para sus lectores franceses e italianos son igualmente cartas.

Exactamente trescientos cincuenta años después de la publicación de los Quarenta aenigmas apareció el libro de Pedro Salinas, Fábula y signo, que tiene también un poema de treinta y tres versos - treinta y dos más un título orgánico para el poema, y enigmático- que también abarca nueve enunciados:

\section{UNDERWOOD GIRLS}

[i] Quietas, dormidas están, las treinta, redondas, blancas.

[ii] Entre todas sostienen el mundo.

[iii] Míralas, aquí en su sueño, como nubes, redondas, blancas, y dentro destinos de trueno y rayo, destinos de lluvia lenta, de nieve, de viento, signos.

[iv] Despiértalas, con contactos saltarines de dedos rápidos, leves, como a músicas antiguas.

[v] Ellas suenan otra música: fantasías de metal, valses duros, al dictado.

[vi] Que se alcen desde siglos todas iguales, distintas como las olas del mar y una gran alma secreta.

[vii] Que se crean que es la carta, la fórmula, como siempre.

${ }^{15}$ Sobre la moda de la carta, véase Claudio Guillén, "Notes toward the study of the Renaissance letter", en Renaissance genres. Essays in theory, history, and interpretation, ed. Barbara Kiefer Lewalski, Harvard University Press, Cambridge, MA, 1986, pp. 71-101. 
[viii] Tú alócate

bien los dedos, y las

raptas y las lanzas,

a las treinta, eternas ninfas

contra el gran mundo vacío,

blanco en blanco.

[ix] Por fin a la hazaña pura,

sin palabras, sin sentido,

ese, zeda, jota, $i \ldots$.

(Fábula y signo, 1931) ${ }^{16}$.

El título del poema se refiere a un recurso de publicidad de la compañía que fabricaba las máquinas de escribir "Underwood" y que resultó ser un gran éxito en 1930. En salas de exposiciones se agrupaba a las mecanógrafas, distribuidas en filas para representar el teclado de una máquina, mostrando, cada una, una especie de redondel con una letra del alfabeto o un símbolo impresos. La fotografía de las gilrs se divulgó bastante en la prensa popular. Era posible reconocer en esos redondeles formas parecidas a las nubes estilizadas de los cuadros contemporáneos, los de Salvador Dalí, por ejemplo, y "las olas del mar" en la disposición lineal de las teclas.

En Underwood girls es interesante examinar los verbos que denotan cierto erotismo en pensamiento o acción: despertar con contactos, alocarse los dedos, y raptar y lanzar. A su manera, este poema se refiere al escritor que llega a ser poeta por influencia secreta de Eros, a la composición que llega a ser creación original obedeciendo a sus pulsiones. El simbolismo de las nubes intuye la violencia -lo que en 1581 se llamó l'eroico furore- del milagro poético. Mientras las nubes están quietas, dormidas, nada se puede esperar de ellas; una vez despiertas se produce en ellas algo como turbulentos efectos atmosféricos, molécula chocando contra molécula, pulsión contra pulsión, palabra todavía sin sentido, no más que letras indescifrables, contra palabra. Son las letras, los signos: ¿cuál sería entonces, para hacer la pregunta en términos del título de la colección, la fábula? Cabe referirse al enigma del verso y a una gran alma secreta. Bien puede hermanarse esta frase con alguna sacada de los textos neoplatónicos que evocaban un absoluto inmanente, el anima mundi ${ }^{17}$. Sólo que en las

16 Pedro Salinas, Poesías completas, Alianza, Madrid, 1989, t. 1, pp. 132-133.

${ }^{17}$ En el contexto de la idea del trasfondo de una composición poética, la expresión músicas antiguas trae a la mente la neoplatónica musica mundana, ese como andamiaje del universo. No está en la Aenigma primera, pero, en el mismo libro, la Aenigma 28 [f. 24r], obra de otro ingenio, ostenta la pregunta: "Qual es la musica mas substancial / Que al mundo consuela...?” Enseguida, la "Exposición 28” [f. 24v]: "Esta musica es la concordia harmonial que ay enel mundo por providencia Divina que haze que los unos son lettrados, los otros guerreres [ sic], otros labradores y otros officiales 
décadas de los años viente y treinta del siglo xx se relacionaría, antes que todo, con el inconsciente, concepto común entre los adeptos del psicoanálisis, entre otros.

El inconsciente sería ese gran depósito bullicioso, incitado por la libido, fuente de los deseos instintivos y del imprescindible élan vital, y lugar de origen, se creía firmemente, de la obra de arte y la literatura imaginativa ${ }^{18}$. En este misterioso lugar, por medio de las teclas de la máquina, el escritor despierta con sus dedos locos, como en un acto amoroso, rapta y lanza contra el vacío, blanco en blanco, las letras, las eternas ninfas ${ }^{19}$. Esta expresión de Salinas parece eco de la de Dante, "Trivia ride tra le ninfe eterne" (Paradiso, XXIII, 26), si bien este verso alude a las estrellas que se alzan agrupadas para acompañar a la luna. Si los escritos son efímeros, las letras son eternas.

Los dos poemas, dejando a un lado lo fortuito de la semejanza en su configuración, son buenos exponentes de dos maneras de pensar el misterio de la creación poética, y del conformismo de dos épocas de la historia de la cultura: la que obedecía a la moda del neoplatonismo cortesano, y la que lo hacía a las conjeturas acerca del inconsciente. En cada caso, siendo el enigma en sus orígenes -si hemos de seguir a Jolles-, una pregunta dirigida al iniciado o no en alguna cofradía o misterio, los dos poemas son preguntas que sondean la adhesión del lector a los respectivos conformismos.

Por la primavera de 1930 empezaron los dos poemas, sin saberlo el poeta ni sus lectores, a vivir vidas paralelas ${ }^{20}$, y Fábula y signo estaba listo para publicarse, en Ediciones Plutarco.

Alan Soons

Massachusetts Center for Renaissance Studies,

Amherst

de muchos artes, / y que cada uno de estos, y todos juntos, / reconoscen y obedecen à sus Principes, y créen [a] alguna Divinidad”. Se percibe aquí un sustento del absolutismo. En efecto, 1581 fue el año de la publicación de la traducción al francés del tratado "monarcómaco" Vindiciae contra tyrannos de Duplessis-Mornay.

18 Una noción comprensiva de las ideas sobre el inconsciente entre los poetas como fuente de la creación en aquellos años se lee en PIERRE TRAHARD, Le mystère poétique, Nizet, Paris, 1970, pp. 55-58 y 84-86. Aunque en un texto sobre los enigmas publicado un poco más tarde, GaSTON BACHELARD sostiene que: "On ne peut penser longtemps à un mystère, à une énigme, à une entreprise chimérique, sans en sexualiser" (La formation de l'esprit scientifique, 6 $6^{\mathrm{a}}$ éd., Vrin, Paris, 1969, p. 185).

${ }^{19} \mathrm{El} D R A E$, s. v. blanco, dice (acepción 18): "Fin u objeto a que se dirigen nuestros deseos o acciones", además, sobre en blanco: "Dícese del libro, cuaderno u hoja que no están escritos o impresos", y claro está, dar en el blanco.

${ }^{20}$ Esta expresión "plutarquesca" asoma por casualidad en carta de Salinas a Jorge Guillén, fechada el 30 de abril 1930: “...como yo he continuado también escribiendo todo este tiempo, el recibir tus poemas fue un capítulo más de las vidas paralelas" (Pedro Salinas /Jorge Guillén. Correspondencia. 1925-1951, Tusquets, Barcelona, 1992, p. 109). 